\title{
Fibrinogen as a replacement therapy in
}

bleedina disorder.

\section{Dr .Rasha Magdy Mohamed Said.MD,}

\section{Lecturer of internal medicine and haematology department, Ain Shams University}

Fibrinogen by its role in clot formation and stabilization via its conversion to fibrin catalyzed by thrombin and also by induction of platelet activation and aggregation by binding to the platelet fibrinogen receptor glycoprotein GPIIb/Illa strengthing the clot formed. ${ }^{(11)}$

Its supplementation is indicated as prophylaxis and therapy of haemorrhage in congenital and acquired fibrinogen deficiency ${ }^{(18) .}$

Supplementation of fibrinogen can be provided by transfusion of fresh-frozen plasma (FFP), cryoprecipitate and fibrinogen concentrate .(16) $^{-(19)}$

FFP has several limitations including a low fibrinogen content, so large volumes to be given, and the risk of transfusion-related complications (e.g., transfusion-related acute lung injury [TRALI] and viral transmission).

Fibrinogen concentrate its content of fibrinogen is standardized, cross-matching is not required In contrast to FFP and cryoprecipitate ${ }^{.(4)}$

Haemocomplettan (commercialised in the USA as RiaSTAP) ${ }^{(8)}$, is the type which is widely used and was effective in both the treatment of spontaneous bleeding episodes and as prophylaxis before surgical procedures or against spontaneous bleeding in patients with congenital fibrinogen deficiency ${ }^{(1)}$

Fibrinogen can be dosed based on the level of bleeding and initial fibrinogen concentration. perioperatively, 1 to $2 \mathrm{~g}$ should be administered initially if bleeding is accompanied by suspected low fibrinogen concentrations or function ${ }^{\left({ }^{(9)}\right.}$

The fibrinogen dose can be calculated as follows: Fibrinogen concentrate dose $(\mathrm{g})=$ [target FIBTEM MCF(maximum clot firmness) $(\mathrm{mm})$ - actual FIBTEM MCF $(\mathrm{mm})] \times$ [body weight $(\mathrm{kg}) / 70] \times 0.5 \mathrm{~g} / \mathrm{mm}$.

Normal MCF values are 9 to $25 \mathrm{~mm}$ that correlate with normal fibrinogen levels; however, a target MCF of $22 \mathrm{~mm}$ has been used in aortic surgery patients (achieved using mean fibrinogen doses of $5.7 \mathrm{~g}^{(13) .}$ 
$25 \mathrm{mg} / \mathrm{kg}$ fibrinogen concentrate is recommended if EXTEM A10 and FIBTEM A10 are below $40 \mathrm{~mm}$ and $8 \mathrm{~mm}$, respectively. If FIBTEM A10 is $<6 \mathrm{~mm}$ and EXTEM A10 is $<40 \mathrm{~mm}$, the recommended dose increases to $50 \mathrm{mg} / \mathrm{kg}^{.(20)}$

Thromboembolic event associated with administering excessive fibrinogen, particularly with high thrombin generation, may increase the risk of systemic microthrombogenicity.

However, no reports of hypercoagulability or thromboembolism following treatment with fibrinogen levels up to $600 \mathrm{mg} / \mathrm{kg}^{\cdot(10)}$

To be highlighted that recombinant activated factor VII, used for the treatment or prevention of bleeding in patients with acquired and congenital haemophilia with inhibitors or with other inherited bleeding disorders, requires a fibrinogen level of $\geq 1 \mathrm{~g} / \mathrm{L}$ as a pre-condition for optimal haemostatic activity. ${ }^{(12)}$

Acquired hypofibrinogenaemia, such as following trauma,Fibrinogen and other factor concentrates are increasingly being studied and reported in surgical and trauma algorithms as a management protocol for treating hemorrhage. Goal-directed coagulation management using fibrinogen concentrates and PCCs improved survival rates as compared with those predicted by the Trauma Injury Severity Score in a retrospective report of 131 patients. ${ }^{(14)}$

A study evaluating 144 patients with major blunt trauma reported coagulation factor concentrates corrected coagulopathy and reduced RBC and platelet transfusion compared with those receiving FFP, and fewer patients developed multiorgan failure. ${ }^{(6)}$

However, overall mortality was not reduced with fibrinogen concentrates in another retrospective study of 294 trauma patients. ${ }^{(19)}$

More recent European trauma guidelines from 2013 recommend fibrinogen administration at levels $<1.5$ to $2.0 \mathrm{~g} / \mathrm{L}$. ${ }^{(15)}$

In cardiothoracic surgeryPreoperative fibrinogen concentrations $<3 \mathrm{~g} / \mathrm{L}$ are reported to increase perioperative blood loss and transfusion requirements after coronary artery bypass grafting. ${ }^{(7)(5)}$

Fibrinogen repletion will reduce bleeding and the need for allogeneic blood products. Other prospective and retrospective cardiac surgical studies, including highrisk ascending aortic replacement surgery, report that fibrinogen repletion with concentrates reduces postoperative bleeding and allogeneic blood product administration . ${ }^{(17)}$

In obstetric haemorrhage as an important cause of maternal mortality, Multiple studies reported reduced levels of fibrinogen associated with the progression of $\mathrm{PPH}$ (postpartum hemorrhage) in study of 356 women even lower fibrinogen and FIBTEM A5 values were associated with more prolonged bleeds, especially when FIBTEM was $<10 \mathrm{~mm}$ or fibrinogen $<2 \mathrm{~g} / \mathrm{L}^{(2)}$. 
Patients with severe PPH had significantly lower fibrinogen and prolonged PT. Fibrinogen was the only laboratory value associated with severe $\mathrm{PPH}$, and the risk was 2.63-fold higher for each $1-\mathrm{g} / \mathrm{L}$ decrease.

In study of orthopaedic patients receiving volume replacement, fibrinogen concentrate restored clotting function, reversing the effects of dilutional coagulopathy. ${ }^{(4)}$

During radical cystectomy efficacy of peri-operatively administered fibrinogen concentrate for excessive bleedingwas found, by increasing clot firmness with reduced post-operative transfusion of red blood cells. ${ }^{(4)}$

Finally,evidence documenting the benefit of fibrinogen concentrate as treatment/prophylaxis of bleeding in congenital fibrinogen deficiency, the preliminary results suggesting its potential role in haemorrhagic conditions associated with an acquired hypofibrinogenaemic state confirmed by additional prospective phase II/III clinical trials focusing on dosing, efficacy and safety ${ }^{(9)}$

\begin{tabular}{|c|c|c|}
\hline Clinical setting & $\begin{array}{l}\text { Trigger for administering fibrinogen } \\
\text { concentrate }\end{array}$ & Fibrinogen dosing \\
\hline \multirow[t]{6}{*}{ Cardiac surgery } & $\begin{array}{l}\text { Using conventional laboratory } \\
\text { measures: }<200 \text { mg/dL (<2 g/L) }\end{array}$ & $25 \mathrm{mg} / \mathrm{kg}$ \\
\hline & $<150 \mathrm{mg} / \mathrm{dL}(<1.5 \mathrm{~g} / \mathrm{L})$ & $50 \mathrm{mg} / \mathrm{kg}$ \\
\hline & $\begin{array}{l}\text { Using POC: EXTEM A10 <40 mm and } \\
\text { FIBTEM A } 10<8 \mathrm{~mm}\end{array}$ & $25 \mathrm{mg} / \mathrm{kg}$ \\
\hline & $\begin{array}{c}\text { EXTEM A10 }<40 \mathrm{~mm} \text { and FIBTEM A10 } \\
<6 \mathrm{~mm}\end{array}$ & $50 \mathrm{mg} / \mathrm{kg}$ \\
\hline & $\begin{array}{c}\text { EXTEM A10 }<40 \mathrm{~mm} \text { and FIBTEM A10 } \\
<4 \mathrm{~mm}\end{array}$ & $75 \mathrm{mg} / \mathrm{kg}$ \\
\hline & $\begin{array}{c}\text { EXTEM A10 }<30 \mathrm{~mm} \text { and FIBTEM A10 } \\
<4 \mathrm{~mm}\end{array}$ & $\begin{array}{c}75 \mathrm{mg} / \mathrm{kg}+2 \mathrm{PC}+0.4 \mu \mathrm{g} / \mathrm{kg} \\
\text { DDAVP }\end{array}$ \\
\hline \multirow[t]{2}{*}{ Trauma } & FIBTEM CA10 <7 mm & $2-6 g$ \\
\hline & EXTEM CA10 <30 mm & 6-8 $\mathrm{g}$ and PCC 20-30 U/kg BW \\
\hline \multirow[t]{3}{*}{ Liver transplantation } & $\begin{array}{l}\text { Massive diffuse bleeding and EXTEM } \\
\qquad M C F<25 \mathrm{~mm}\end{array}$ & $\begin{array}{c}\text { Fibrinogen concentrate,- } \mathrm{PC} \text { and } \\
\text { PCC }\end{array}$ \\
\hline & $\begin{array}{c}\text { EXTEM MCF }<35 \mathrm{~mm} \text { and FIBTEM } \\
\qquad \mathrm{MCF}<8 \mathrm{~mm}\end{array}$ & $\begin{array}{c}25 \text { mg/kg (or cryoprecipitate); } 50 \\
\mathrm{mg} / \mathrm{kg} \text { if FIBTEM MCF <4 mm }\end{array}$ \\
\hline & $\begin{array}{l}\text { EXTEM MCF }<45 \mathrm{~mm} \text { and FIBTEM } \\
\qquad \mathrm{MCF}<8 \mathrm{~mm}\end{array}$ & $\begin{array}{c}25 \mathrm{mg} / \mathrm{kg} \text { (or cryoprecipitate); } 50 \\
\mathrm{mg} / \mathrm{kg} \text { if FIBTEM MCF <4 mm }\end{array}$ \\
\hline
\end{tabular}




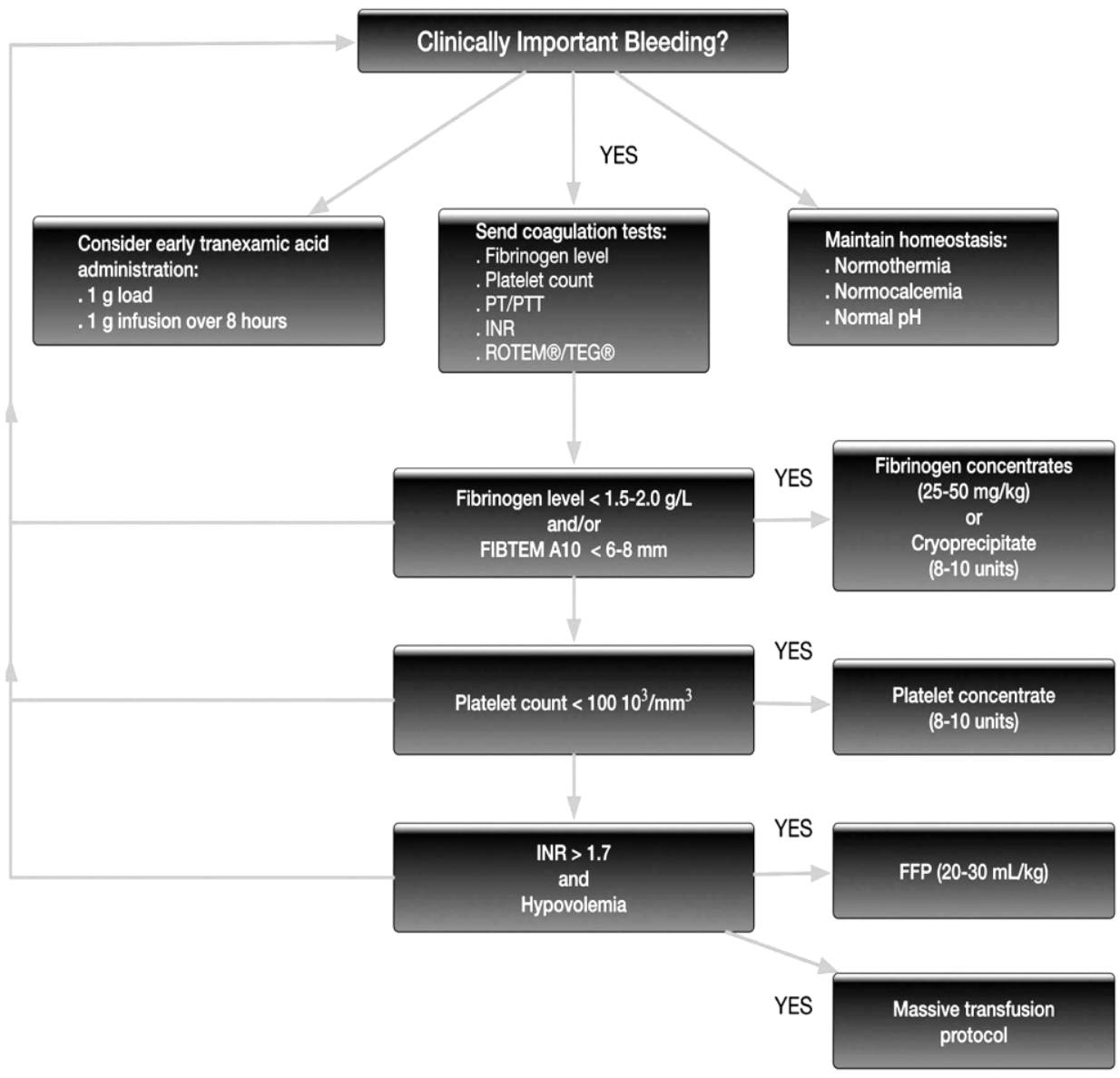

Fig (1) Fibrinogen algorithm. Suggested management strategy for the bleeding patient and repletion strategies.

\section{$\underline{\text { Reference }}$}

1. Bell SF, Rayment R, Collins PW, Collis RE. The use of fibrinogen concentrate to correct hypofibrinogenemia rapidly during obstetric haemorrhage. Int $\mathrm{J}$ Obstet Anaesth. 2010;19:218-23.

2. Charbit B, Mandelbrot L, Samain E, et al; PPH StudyGroup. The decrease of fibrinogen is an early predictor of the severity of postpartum hemorrhage. J Thromb Haemost 2007;5(2):266-273.

3. Collins PW, Lilley G, Bruynseels D, et al.Fibrin-based clot formation as an early and rapid biomarker for progression of postpartum hemorrhage: a prospective study.Blood 2014;124(11):1727-1736.

4. Fenger-Eriksen C, Ingerslev J, Sørensen B. Fibrinogen concentrate-a potential universal hemostatic agent. Expert Opin Biol Ther 2009;9(10):1325-1333

5. Massimo Franchini and Giuseppe Lippi. Fibrinogen replacement therapy: a critical review of the literature, Blood Transfus. 2012 Jan; 10(1): 23-27. 
6. Innerhofer $\mathrm{P}$, Westermann I, Tauber $\mathrm{H}$, et al. The exclusive use of coagulation factor concentrates enables reversal of coagulopathy and decreases transfusion rates in patients with major blunt trauma. Injury 2013;44(2):209-216.

7. Karlsson M, Ternström L, Hyllner M, et al. Prophylactic fibrinogen infusion reduces bleeding after coronary artery bypass surgery. A prospective randomised pilot study. Thromb Haemost 2009;102(1):137-144.

8. Kreuz W, Meili E, Peter-Salonen K, et al. Efficacy and tolerability of a pasteurised human fibrinogen concentrate in patients with congenital fibrinogen deficiency. Transfus Apher Sci. 2005;32:247-53.

9. Jerrold H. Levy and Lawrence T. Goodnough. How I use fibrinogen replacement therapy in acquired bleeding.February 26,2015:Blood:125(9).

10. Martini J, Maisch S, Pilshofer L, Streif W, Martini W, FriesD. Fibrinogen concentrate in dilutional coagulopathy: a dose study in pigs. Transfusion 2014;54(1):149-157.

11. Mosesson MW. Fibrinogen and fibrin structure and functions. J Thromb Haemost. 2005;3:1894-904.

12. Procoagulators. Transfus.Med.Hemother. 2009;36:419-36.

13. Rahe-Meyer N, Pichlmaier $M$, Haverich $A$, et al. Bleeding management with fibrinogen concentrate targeting a high-normal plasma fibrinogen level: a pilot study. $\mathrm{Br} \mathrm{J}$ Anaesth 2009;102(6):785-792.

14. Schöchl H, Forster L, Woidke R, Solomon C, Voelckel W. Use of rotation thromboelastometry (ROTEM) to achieve successful treatment of polytrauma with fibrinogen concentrate and prothrombin comple concentrate. Anaesthesia2010;65(2):199203.

15. Solomon $\mathrm{C}$, Schöchl $\mathrm{H}$, Hanke A, et al. Haemostatic therapy in coronary artery bypass graft patients with decreased platelet function: comparison of fibrinogen concentrate with allogeneic blood products. Scand J Clin Lab Invest 2012;72(2):121-128.

16. Sørensen B, Bevan D. A critical evaluation of cryoprecipitate for replacement of fibrinogen. Br J Haematol. 2010;149:834-43.

17. Spahn DR, Bouillon B, Cerny V, et al. Management of bleeding and coagulopathy following major trauma: an updated European guideline. Crit Care 2013;17(2):R76.

18. Tziomalos K, Vakalopoulou S, Perifanis V, Garipidou V. Treatment of congenital fibrinogen deficiency: overview and recent findings. Vasc Health Risk Manag. 2009;5:843-8.

19. Wafaisade A, Lefering R, Maegele M, et al; Trauma Registry of DGU. Administration of fibrinogen concentrate in exsanguinating trauma patients is associated with improved survival at 6 hours but not at discharge. J Trauma Acute Care Surg2013;74(2):387-3, discussion 393-395.

20. Weber CF, Zacharowski K, Meybohm P, et al. Hemotherapy algorithms for coagulopathic cardiac surgery patients. Clin Lab 2014;60(6):1059-1063. 